\section{RHEUMATIC NODULES (RHEUMATISMUS NODOSUS) ASSOCIATED WITH RHEUMATIC TORTICOLLIS.}

BY F. PARKES WEBER, M.D., F.R.C.P., SENIOR PHYSICIAN TO THE GERMAN HOSPITAL, LONDON.

The connexion of rheumatic nodules with rheumatic polyarthritis and Sydenham's chorea has, of course, long been recognized. Barlow and Warner, at the International Medical Congress at London in 1881, read a paper on subcutaneous nodules connected with fibrous structures occurring in children the subjects of rheumatism and chorea $;^{1}$ it was based on 27 cases collected by themselves. H. Rabinowitsch, in an inaugural dissertation at Berlin in $1889,{ }^{2}$ collected accounts of 52 cases, of which 44 were under the age of 20 . If the German term rheumatismus nodosus (nodular rheumatism) be employed for this variety of rheumatism, it must, of course, not be

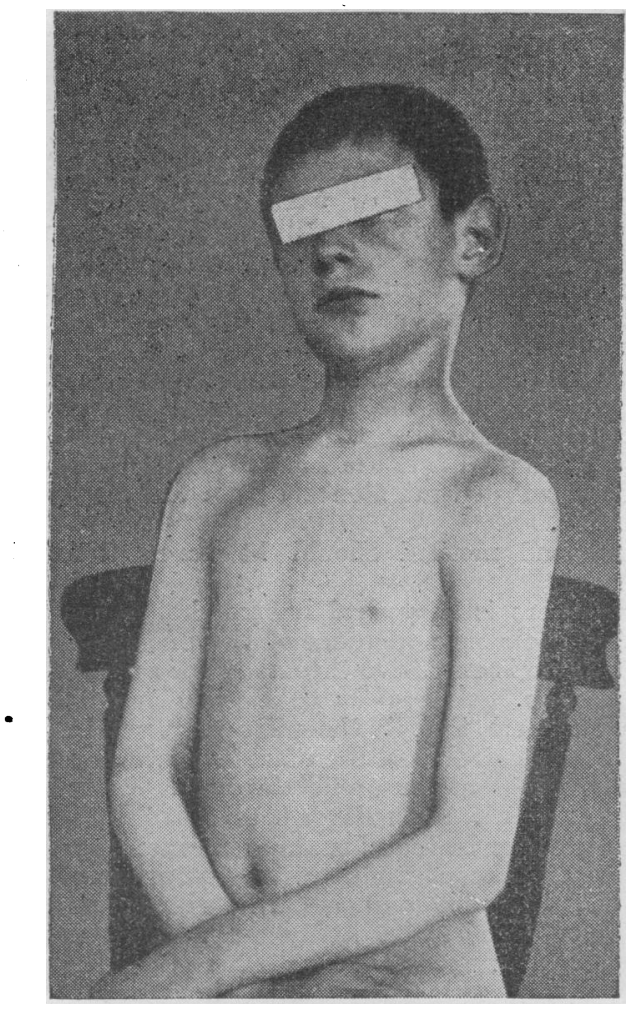

Fis. 1.-To show the wry-neck.

confused with the French rhumatisme noucux, which is a synonym for arthritis deformans. True rheumatic nodules are termed by the French nodosités rhumatismales souscutanées. $^{3}$

One of the most elaborate and recent paper's on the subject is that by Rosa Berkowitz in 1912, ${ }^{4}$ who based her conclusions on some personal observations and a large collection of cases from the literature. According to her statistics cardiac complications (endocarditis, endopericarditis) are present in at least 88 per cent. of cases of nodular rheumatism in children. In all probability the present case is no exception to the rule that endocarditis generally accompanies rheumatic nodules, though the auscultatory signs are not quite decisive. The case conforms to the rule that the subjects of true rheumatic nodules are generally children who have passed through an acute or subacute rheumatic infection without being completely cured. The special interest in the case is, however, the association of the nodules with rheumatic torticollis, an association which one would expect to be not so very infrequent, but which seems as yet to be unrecorded in the literature of the subject.

F. W., ${ }^{*}$ aged 11 years, is a pale, rather delicate-looking boy, with a certain degree of wry-neck, the neck being bent towards

* The patient was shown by Dr. Weber at the Clinical Section of the Roxal Societv of Medicine on November 14th, 1913 the patient's right with the chin turned a little to the left (see Fig. 1, from a photograph taken on October 19th). At present (November lst, 1913) there is no arthritis, nor does the boy complain of any pain or tenderness anywhere, but there is some puffiness about the second and third metacarpo-phalangeal joints in both hands, and over these joints very small rheumatic noing atic nodules over both elbows and both knees (patellae), those over the knees being the largest and the most numerous. The olecranon bursa at both elbows is enlarged. The heart is excitable in action, and the impurity of the first sound at the apex suggests slight endocardial changes at the mitral valve. In the absence of fever the frequency as well as the excitability of the heart's action suggest slight myocardial implication. There is likewise a variable systolic murmur to be heard ove the "pulmonary area." Some of the lymphatic glands in the neck are a little enlarged.

The history is that the boy enjoyed good health until the present illness commenced on September 13th, 1913, with pain in the left ankle; this joint became swollen on the following day. There was never any tonsillitis. He was treated by rest in bed and small doses of salicylates. At first there was fever up to between $102^{\circ} \mathbf{F}$. and $103^{\circ} \mathrm{F}$. This left him on September 20 th, but after September 24th to the middle of October there were occasional evening rises of temperature to about $100^{\circ} \mathrm{F}$. vere occasional evening rises of tem
Since then there has been no fever.

The wry-neck appeared at the end of September, and was at: first accompanied by a little pain at the lower posterior part of the right side of the neck. The rheumatic nodules were first noticed in the middle of October, at first only on the elbows and knees, later over the hands also. Recently he has been treated with subcutaneous injections of "rheumatism phylacogen" (Parke, Davis, and Co.), and with careful massage of the neck. Roentgen-ray examination (skiagrams), about the middle of October, and again about the middle of November, showed no bony change in the neck. The bony prominence felt on the left side of the neck just below the mastoid region is evidently due merely to the wry-neck position of the cervical vertebrae.

When the case was shown on November 14th the rheumatic

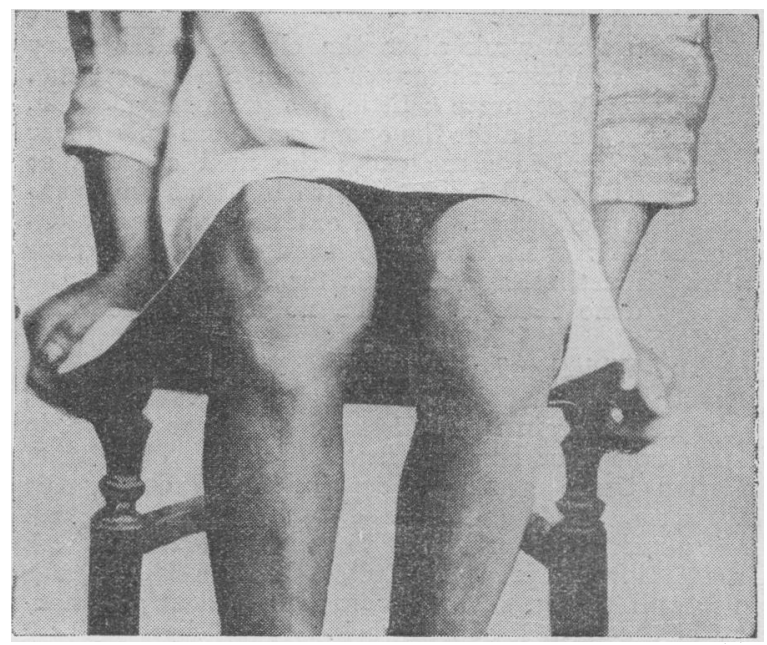

Fig. 2.-To show the rheumatic nodules ou the knees.

nodules on the elbows and hands had become less marked, but those on the knees had, if anything, increased (Fig. 2). The wry-neck had not disappeared entirely. The phylacogen treatment had been accompanied by occasional very slight febrile reaction.

'The boy's father died five years ago from pulmonary tuberculusis at the age of 3.9 , and the mother, aged 45 , is living and well. Their four children are all living and the paticnt is the only one of them who is not well.

Similar "rheumatic torticollis," occurring after a mild attack of acute rheumatism, has not rarely been diagnosed as due to tuberculous caries of cervical vertebrae, and treated accordingly.

Perhaps a true periarthritic rheumatic fibrositis, analogous to the fibrositis which produces the rheumatio nodules, is the cause of the torticollis, which in the present case has not ceased during sleep, has not been intermittent and has not been associated with any clonic or other spasm.

It is interesting that in $1878 \mathrm{H}$. Rehn ${ }^{5}$ ended his sum. mary of the local manifestations of acute rheumatism with a description of rheumatic wry-neck, and the first two published cases of rheumatic nodules (P. Meynet's of 1875 and one observed by himself). I have not thought it advisable to remove any of the nodules for histological examination. There seem to be quite sufficient observa. tions of the kind on record, and the anatomical patho. 
logical findings have been quite recently clealt with in an excellent paper by Paul Frank. ${ }^{6}$

REFERENCES.

1 Barlow and Warner, Trans. Seventh Internat. Mell. Congress, London, 1881, vol. iv, p. 116. 2 Beiträge zur Kenntnis des Rheum atismus mit Knötchenbiláung (Rhelumatismus nodosus). ${ }^{3}$ Cf. E Troisier, mit vol. xil, p. . E. Troisler and L. Broca, Rethe de medecine, Paris, 1881 le l. p. le lana, Paris, 14. L Delachanal. Stuttert 1912 ol lix $\mathrm{pp}, 13,5 \mathrm{H}$. der Kinclortion 6 P. Frank, U.ber den Rheumatismus nodosus mit besonder Beriicksichtigung des pathologisch anatomischeu Befundes, Berline lilin.-Wochenschr., 1912, Jahrgang xlix, p. 1358.

\section{THE DAILY WEIGHT CHART AS A GUIDE TO TUBERCULIN.}

BY H. WARREN CROWE, M.D.OxoN., YELIVEHTON, DEVON

ONE of the greatest problems in raccine treatment is the dosage of tubercuiin. How are the size of the dose and the interval to be regulated? There are various methors, divisible roughly into two groups: (1) By clinical observation, coupled with experience; (2) by serological tests. Neither of these is entirely satisfactory. The former because the experience required is beyond the reach of most of us, and no amount of experience will tell infallibly what interval is the best; frequently, too, clinical observa. tions are of no assistance, since there may be no clinical facts to observe; the temperature may be unaltered; the pulse-rate unaffected, the focus of disease too deep for changes in physical signs to be detected. How, then; is one to know at what interval to give the next dose? 'In the result one has to chance it. On the other hand, sero. logical tests in phthisis, at any rate, are useless as a guide to therapy unless frequently repeated, and this I talie it to be, for the majority, outside the range of practical treatment.

The object of this communication is to bring forward a method which is as nearly an infallible guide to correct tuberculin treatment as we are ever likely to obtain, and which happily is so simple that there is no case to which it cannot be applied.

If a chart is bept on which the weight, taken daily at the same hour and in the same garments, is recorded, fluctia-

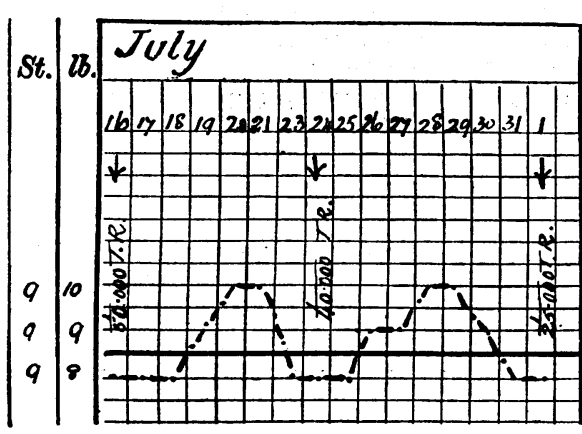

Chart 1.-Showing fluctuations induced by two small doses of tuberculin ix a case of carly phthisis. tions will be found to occur. These are not con fined to small differences of an ounce or two, but from half to as much as two pounds may be noted be. tween suc. ceeding days.

On compar. ing weight charts of cases con. trolled by this

method over a period of some two years or more, I have found that the weight curves, following a dose of tuber. culin, fall naturally into the following groups (Chart 2). (Each perpendicular indicates an interval of twenty-four hours.)

What, now, is the meaning of these rather remarkable fluctuations in the daily weight? One notices at once the curious resemblances these curves bear to immunity curves, such as may be obtained by a series of opsonic indices. In 3 and 5 one sees short and long negative phases; in 4 the pre-negative rise, often so marked in plithisis; in 6 and 7 the irregular waxing and waning of immunity following an unsuitable raccine, and usually incticating active autoinoculation. Opsonic records abound in curves similar to these here indicated. Is it possible that these weight curves are immunity curves? From the appearance of them one would not be surprised to find this to be the case. The proof also is not far to seek, for it remains only to plot an immunity curve by opsonic estimations of the blcod, taken at the same time as the weight.

Chart 3 is a record of the daily weight and opsonic index in a case of (4) carly plithisis, with very slight signs at the left apex; no secondary infection. It is typical of a large number which (6) have been plotted, and shows in a most striking manner that the weight. curve (broken line) (y) pursues an undulating curve in detail almost iclentical with that of the opsonic content of the blood (continin ous line).

Herein, then, is

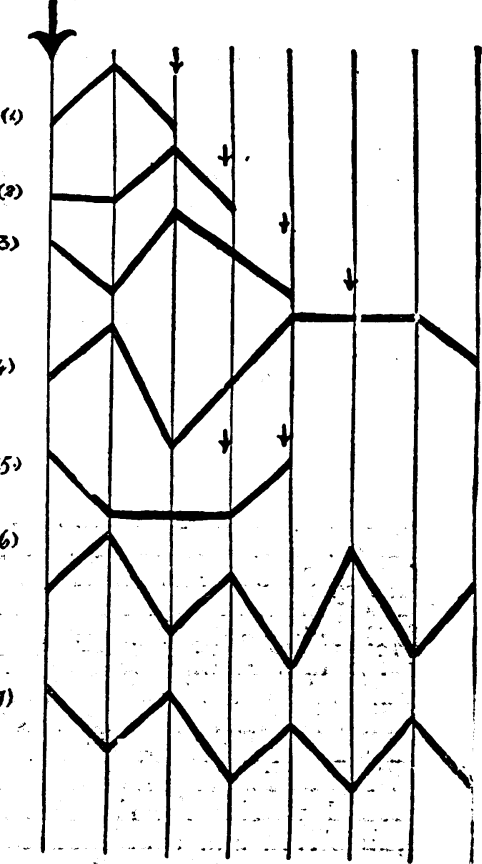

Chart 2.-Showing weight curves follow ing tuberculin. provided for - $t$ the proof that the daily weight curve is an immunity curve, and as such a rational metho for controlling treatment by tuberculin. But this cliar illustrates also a further point which is of consider. able importance, and that is that the weight is not quie so sensitive as the opsonic index. The only point at which the curves of index and weight differ occurs immediately after the first $d$ : se, the index showing a short regative pliase, the weiglit, on the contrary, rising. The patieut had no symptonis suggesting a serious negative phase. If the weight falls after a dose (see response to third dose) the patient frequ ntly complains of malaise." In either case one must presuppose a negative phase. When, how ever, the weight does not drop, such negative phase may

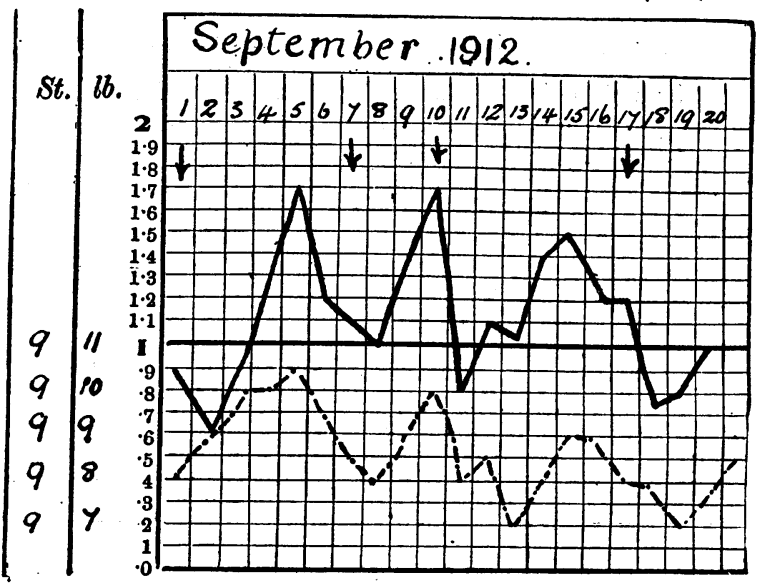

Chart 3.-Showing daily weight and opsonic index. Doses of T.R.

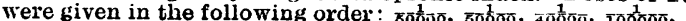

be disregarded; not so where the weight curve shows a fall. Then, again, the weight chart, by reason of the continued fall, gave a better indication that dose 3 was too large than the opsonic index. One further advantage possessed by a record of the weight over the index may be noted, and that is the general rise which may take place over a prolonged period, showing general improvement. The index, on the contrary, remains within certain limits, and gives no indication of general improvement or the reverse. One readily calls to mind cases in which a 